\title{
Disturbances in ocular sympathetic function and facial blood flow in unilateral migraine headache
}

\author{
Peter D Drummond
}

\begin{abstract}
The relationship between thermographic asymmetry in various parts of the face and indices of ocular sympathetic outflow was examined in 80 patients with unilateral migrainous headache. Both during and between episodes of headache, the pupil on the symptomatic side dilated more slowly and less extensively in darkness than the opposite pupil, indicating that ocular sympathetic outflow was compromised in some patients. In such cases the upper forehead and orbital region were warmer on the symptomatic side during migraine. In contrast to these signs of a reduction in cervical sympathetic outflow, eyelid separation was greater on the symptomatic side in patients with headache on the side that was usually affected. During the headache-free interval no consistent thermographic asymmetry was detected and eyelid separation was similar on both sides. These findings suggest that extracranial vascular changes and ocular sympathetic dysfunction during migraine are secondary to activation of trigeminal-vascular reflexes or to antidromic release of vasoactive substances from trigeminal nerve terminals. A secondary deficit in the sympathetic pathway to the symptomatic pupil could also prevent the expression of an increase in sympathetic outflow during headache.
\end{abstract}

The studies of Graham and Wolff ${ }^{1}$ established that dilatation of large scalp arteries contributes to the pain of migraine headache, although more recent evidence indicates that such changes are not necessarily the primary source of pain in every case. ${ }^{2}$ In our laboratory, thermographic signs of increased facial blood flow in areas affected by unilateral migraine or tension-vascular headache were observed in a minority of instances. ${ }^{34}$ In such patients, pulsations recorded from the frontal branch of the superficial temporal artery were greater on the side of the headache, ${ }^{3}$ which was usually described as throbbing and could be alleviated by applying sufficient pressure over the superficial temporal artery to decrease blood flow. ${ }^{4}$ Between episodes of headache facial temperature was distributed symmetrically, although scalp arteries still dilated readily to stimuli such as light exercise and mild psychological stress. ${ }^{5}$

Several mechanisms could influence dilatation of scalp arteries and increases in cutaneous blood flow in migraine headache. For example, head pain could initiate antidromic release of vasoactive substances from trigeminal nerve terminals. ${ }^{6}$ Stimulation of the trigeminal nerve in cats also increases flow through the common carotid artery and skin via a reflex vasodilator pathway in the greater superficial petrosal nerve. ${ }^{7}$ In addition, a decrease in sympathetic vasoconstrictor outflow or an increase in activity in sympathetic vasodilator pathways ${ }^{8}$ could influence facial blood flow.

The sympathetic nervous system appears to be involved in migraine headache. ${ }^{9}$ For example, a sympathetic deficit associated with supersensitivity to adrenergic substances has been identified in pharmacological studies of the pupils, ${ }^{11}$ the cerebral circulation, ${ }^{12}$ the conjunctival vessels ${ }^{13}$ and the systemic circulation $^{11}$ of migraine patients. Whether the sympathetic deficit is greater on the usual side of the headache has not been settled, although in a series of 33 common migraine patients the pupil was found to be smaller on the symptomatic side both during and between headache episodes. ${ }^{14}$ Thus, sympathetic regulation of facial blood flow may be impaired in migraine, more so on the symptomatic side.

The purpose of my investigation was to examine this possibility in patients with unilateral migraine headache. Speed of pupillary dilatation in darkness and constriction to light were used as indices of sympathetic pupillary activity. ${ }^{1516}$ Eyelid separation was used as an additional index of sympathetic tone because sympathetic outflow influences the position of the eyelids. ${ }^{17}$ In the present study, the relationship between these indices of sympathetic activity and facial blood flow (measured thermographically) was investigated during and between episodes of unilateral migraine headache.

\section{Method}

\section{Patients}

The study sample consisted of 80 patients with unilateral headache in the forehead, temple or orbital region at the time of examination. To rule out the possibility of a structural cause of headache, a headache history taken during a standard clinical interview was supplemented by a neurological and general physical examination and, when indicated, appropriate laboratory tests. Cluster headache patients and those with serious visual impairment, a history of eye disease or vascular problems such as stroke were not included in the study.

A migraine headache was preceded by focal 
Table 1 Age and sex distribution in the study sample

\begin{tabular}{lclll}
\hline & $N$ & Male & Female & Age (years) \\
\hline Migraine (migraine attack) & 51 & 9 & 42 & $41 \cdot 6$ \\
Migraine (nonspecific attack) & 21 & 8 & 13 & $41 \cdot 1$ \\
Tension-type headache & 8 & 5 & 3 & $46 \cdot 4$ \\
\hline
\end{tabular}

neurological symptoms, or was associated with vomiting or at least two other symptoms of migraine (nausea, throbbing pain, photophobia or phonophobia). In 21 of 72 patients with a clinical history of migraine, ${ }^{18}$ headache at the time of examination was not associated with the migrainous symptoms listed above (termed "nonspecific attack" in table 1). A further eight patients described a history of, and presented with, unilateral headache associated with few or no additional features of migraine, thus fitting the description of episodic tension-type headache in the International Headache Society classification. ${ }^{18}$ Thirty five of the 80 patients took prophylactic medication regularly and 28 patients had taken one or more forms of medication on the day of examination: analgesics, (13) ergotamine tartrate, (3) antiemetic agents (7) or prophylactic medication (16). Measurements were repeated during the headache-free interval in 35 patients whose headaches usually recurred on the same side and who had been studied previously with headache at the usual site. Informed consent for the procedures was obtained in each case.

\section{Procedures}

To minimise facial sweating, thermographic measurements were obtained in an air-conditioned laboratory maintained at $22 \pm 1^{\circ} \mathrm{C}$. The patient was given at least 20 minutes to adjust to the room temperature and lighting before the first procedure. During this period, details of medication consumption, headache site and associated symptoms were recorded on a standard form.

Facial temperature was detected with an AGA Thermovision 680 camera and displayed on an oscilloscope monitor as seven consecutive isotherms, each separated by $0.5^{\circ} \mathrm{C}$. The difference in temperature between the symptomatic and nonsymptomatic sides of the face was measured to the nearest $0.25^{\circ} \mathrm{C}$ for the upper forehead, supraorbital region (lower two-thirds of the forehead), orbits and cheeks.

Photographs of both pupils were then taken at intervals of 30 seconds on infrared film in a small photographic chamber. Pupil diameter in darkness (0.04 Lux) was recorded for all 80 patients. In 47 cases, the pupils were photographed after the chamber had been illuminated for $0.8,1.6$ or 3.0 seconds with moderately bright light (153.5 Lux, measured with a Mavolux electronic luxmeter at the position of the patients eyes) following 30 seconds of darkness. ${ }^{19}$ Additional photographs were taken 3.0 or 5.0 seconds after the light had been switched off, following 30 seconds of illumination. Patients were instructed to look at a black dot attached to an evenly-illuminated screen 56 $\mathrm{cm}$ away and to stop blinking for a few seconds before each photograph. To average out ran- dom fluctuations in pupil diameter, three photographs were taken for each data point.

Horizontal pupil diameter and the vertical distance between the eyelids in darkness were later measured from the film negative magnified 8.0 times.

\section{Statistical methods}

Thermographic asymmetry and indices of ocular sympathetic outflow during unilateral headache were investigated with analyses of variance containing one between-groups factor arranged as two planned contrasts: migraine patients versus those with episodic unilateral tension-type headache, ${ }^{18}$ and migraine attacks versus nonspecific attacks for patients with a history of migraine. Analyses of pupillary and eyelid data also contained one repeated measures factor (headache versus headachefree side). Additional analyses of variance were computed to investigate the influence of prophylactic medication and medication taken on the day of examination, on pupil and eyelid asymmetry. The relationship between thermographic asymmetry and indices of ocular sympathetic outflow during unilateral headache was investigated with Pearson's correlation coefficient. The difference between the symptomatic and nonsymptomatic sides were computed for patients with headache at the usual site at the time of examination using the $t$ test.

In the headache-free interval, thermographic, pupillary and eyelid asymmetry for patients whose headaches recurred on the same side on at least $70 \%$ of occasions were investigated with paired $t$ tests.

\section{Results \\ During headache}

The pupil on the symptomatic side dilated more slowly in darkness than the opposite pupil and remained smaller after 30 seconds of darkness (table 2). None of the planned contrasts among diagnostic categories achieved statistical significance, indicating that the extent of miosis on the symptomatic side did not differ between patients with migraine or nonspecific headache. In 67 of 80 patients, headaches recurred on the same side for at least $70 \%$ of attacks. In all but five of this group, headache was on the usual side at the time of examination. In the 62 patients with headache at the usual site, pupil diameter after 30 seconds of darkness was smaller on the symptomatic side $(6.01 \mathrm{~mm}$ versus $6.09 \mathrm{~mm}, \mathrm{t}(61)=3.54, \mathrm{p}<$ $0.001)$. In contrast, eyelid separation was greater on the symptomatic side in these patients $(9.1 \mathrm{~mm}$ versus $8.9 \mathrm{~mm}, \mathrm{t}(61)=2.78$, $\mathrm{p}<0.01)$. Regular consumption of prophylactic medication appeared to influence eyelid asymmetry: the distance between the eyelids averaged $8.8 \mathrm{~mm}$ on the symptomatic side and $8.9 \mathrm{~mm}$ on the nonsymptomatic side in 35 patients who took prophylactic medication regularly, whereas in the other 45 patients eyelid separation averaged $9.2 \mathrm{~mm}$ and $9.0 \mathrm{~mm}$ respectively (interaction between group and eyelid asymmetry, $\mathrm{F}(1,78)=4.74, \mathrm{p}<0.05)$. 
Table 2 Pupil and eyelid asymmetry during unilateral headache

\begin{tabular}{|c|c|c|c|c|c|}
\hline & \multirow[b]{2}{*}{$N$} & \multicolumn{2}{|r|}{ Mean ( $S D$ ) } & \multirow[b]{2}{*}{ Fratio } & \multirow[b]{2}{*}{$P$} \\
\hline & & Symptomatic side ( $\mathrm{mm}$ ) & Nonsymptomatic side ( $\mathrm{mm}$ ) & & \\
\hline $\begin{array}{l}\text { Pupils } \\
\text { After } 3 \cdot 0 \text { s light } \\
\text { After } 1 \cdot 6 \mathrm{~s} \text { light } \\
\text { After } 0 \cdot 8 \mathrm{~s} \text { light } \\
\text { After } 3 \cdot 0 \mathrm{~s} \text { darkness } \\
\text { After } 5 \cdot 0 \mathrm{~s} \text { darkness } \\
\text { After } 30 \mathrm{~s} \text { darkness } \\
\text { Eyelids } \\
\text { After } 30 \text { s darkness }\end{array}$ & $\begin{array}{l}47 \\
47 \\
47 \\
47 \\
47 \\
80 \\
\\
\end{array}$ & $\begin{array}{l}3.02(0.37) \\
3.57(0.53) \\
4.30(0.70) \\
4.42(0.55) \\
4.87(0.62) \\
6.05(0.74) \\
\\
9.05(1.55)\end{array}$ & $\begin{array}{l}3.04(0.37) \\
3.58(0.52) \\
4.35(0.68) \\
4.48(0.53) \\
4.95(0.59) \\
6.13(0.71)\end{array}$ & $\begin{array}{r}0 \cdot 74 \\
0 \cdot 23 \\
1 \cdot 28 \\
5 \cdot 40 \\
5 \cdot 71 \\
11 \cdot 82 \\
\\
2 \cdot 79\end{array}$ & $\begin{array}{l}- \\
- \\
<0.05 \\
<0.05 \\
<0.001 \\
-\end{array}$ \\
\hline
\end{tabular}

Medication taken on the day of examination had no consistent effect on pupil or eyelid asymmetry.

Fàcial temperature did not differ consistently between the symptomatic and nonsymptomatic sides in any of the areas studied for any of the three diagnostic categories. In previous investigations $\mathbf{s}^{34}$ the upper part of the forehead was warmer on the symptomatic side in a subgroup of patients whose headache was throbbing. Similar results were obtained in this investigation (table 3 ). In addition, heat loss from the orbital region was greater on the symptomatic side in patients with throbbing headache (table 3 ).

Pupil asymmetry during unilateral headache was closely related to asymmetry of the palpebral fissures (table 4). Thus, pupil diameter and rate of dilatation in darkness were diminished on the symptomatic side in patients with subclinical ptosis. In such cases the upper part of the forehead and, less consistently, the orbital region was warmer on the symptomatic side (table 4).

\section{Headache-free interval}

Pupillary measurements were carried out during the headache-free interval in 35 patients whose headaches usually recurred on the same side. Pupillary light reflexes were measured in 17 of this group. Pupil diameter was smaller on the usual side of the headache, but eyelid separation was similar on the two sides (table 5). No consistent thermographic asymmetry was detected during the headache-free interval and heat loss from the upper forehead and orbits was symmetrical in patients who had been examined previously during throbbing headache.

\section{Discussion}

The pupillary findings indicated that a subclinical ocular sympathetic deficit was present on the side of headache in the majority of patients. Fanciullacci ${ }^{10}$ suggested that ocular sympathetic dysfunction in migraine could mirror impairment in central monoamine pathways involved in the production of head pain. Alternatively, peripheral disturbances may impede ocular sympathetic outflow. For example, dilatation of the internal carotid artery or swelling of its arterial wall during migraine could compress the plexus of sympathetic fibres surrounding the artery, particularly in the region of the carotid canal. ${ }^{20}$ This may release sympathetic vasoconstrictor tone. In cats, stimulating the trigeminal nerve or brainstem centres such as the locus coeruleus increases blood flow through the common carotid artery and cutaneous circulation via a reflex pathway in the greater superficial petrosal nerve. ${ }^{21}$ The pain of migraine headache could initiate this reflex, ${ }^{7}$ or could cause antidromic release of vasoactive substances from trigeminal nerve terminals. ${ }^{6}$ Signs of ocular sympathetic deficit on the side of the headache were associated with thermographic signs of increased perfusion, both in this study and in cluster headache patients studied during attacks. ${ }^{22}$ Thus, local increases in facial blood flow in migraine and cluster headache may be due to hyperactivity in trigeminal pathways with secondary reduction in sympathetic vasoconstrictor tone.

Miosis on the usual side of the headache persisted during the headache-free interval in the present series of patients, but this finding was not confirmed in a sample of community volunteers (unpublished observations). If disturbances in ocular sympathetic function in migraine headache are secondary to other processes, they may be most apparent in patients whose headaches are severe enough to warrant neurological attention.

Fanciullacci et $a l^{2}$ reported recently that electrical stimulation of the infratrochlear nerve caused a unilateral decrease in pupil area of $20 \%$ in normal volunteers which persisted for three to four minutes. This response presumably was due to antidromic discharge of iris trigeminal fibres. A similar reaction could have contributed to miosis during headache, but does not account for the persistence of miosis during the headache-free interval.

In contrast to the pupillary findings, examin-

Table 3 Thermographic asymmetry in relation to throbbing headache

\begin{tabular}{lllll}
\hline & \multicolumn{2}{l}{ Thermographic asymmetry $\left({ }^{\circ} \mathrm{C}\right)(S D)$} & & \\
\cline { 2 - 5 } & \multicolumn{1}{l}{ Throbbing headache } & \multicolumn{1}{l}{ Constant headache } \\
& $(N=35)$ & $(N=43)$ & t-test & $P$ \\
\hline Upper forehead & $0.11(0.35)$ & $-0.05(0.32)$ & 2.19 & $<0.05$ \\
Lower forehead & $0.04(0.32)$ & $-0.03(0.30)$ & 0.91 & $<0.001$ \\
Orbits & $0.18\left(0.29^{2}\right)$ & $-0.06(0.32)$ & 3.41 & - \\
Cheeks & $0.06(0.37)$ & $0.03(0.41)$ & 0.32 & \\
\hline
\end{tabular}

2Symptomatic side warmer than opposite side $(p<0.001)$. 
Table 4 Correlation between thermographic and pupillary asymmetry during unilateral headache

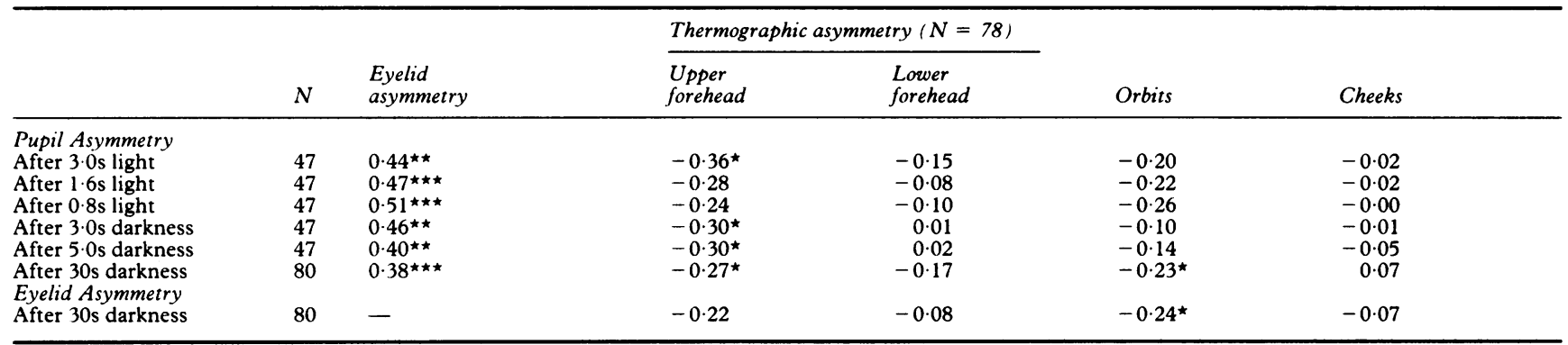

Difference between the symptomatic and nonsymptomatic sides.

${ }^{\star} \mathrm{p}<0.05 ;{ }^{\star \star} \mathrm{p}<0.01 ;{ }^{\star \star \star} \mathrm{p}<0.001$

Table 5 Pupil and eyelid asymmetry during the headache-free interval

\begin{tabular}{|c|c|c|c|c|c|}
\hline & \multirow[b]{2}{*}{$N$} & \multicolumn{2}{|r|}{ Mean ( $S D$ ) } & \multirow[b]{2}{*}{$t$-test } & \multirow[b]{2}{*}{$P$} \\
\hline & & Symptomatic side ( $\mathrm{mm}$ ) & Nonsymptomatic side ( $\mathrm{mm}$ ) & & \\
\hline \multicolumn{6}{|l|}{ Pupils } \\
\hline After $3.0 \mathrm{~s}$ light & 17 & $3.16(0.49)$ & $3.18(0.51)$ & 0.75 & - \\
\hline After $1.6 \mathrm{~s}$ light & 17 & $3.65(0.66)$ & $3.70(0.67)$ & $2 \cdot 12$ & $<0.06$ \\
\hline After $0.8 \mathrm{~s}$ light & 17 & $4.42(0.89)$ & $4.50(0.85)$ & 2.05 & $<0.06$ \\
\hline After 3.0 s darkness & 17 & $4.59(0.52)$ & $4.62(0.49)$ & 0.89 & - \\
\hline After 5.0 s darkness & 17 & $5.00(0.59)$ & $5.09(0.53)$ & $2 \cdot 08$ & $<0.06$ \\
\hline $\begin{array}{l}\text { After } 30 \text { s darkness } \\
\text { Eyelids }\end{array}$ & 35 & $6.13(0.81)$ & $6.24(0.83)$ & $3 \cdot 11$ & $<0.01$ \\
\hline After 30s darkness & 35 & $9 \cdot 36(1.46)$ & $9 \cdot 36(1.46)$ & 0.06 & - \\
\hline
\end{tabular}

ation of eyelid asymmetry suggested that sympathetic activity was greater on the side of the headache in some instances, particularly in patients who did not take prophylactic medication regularly. Thus, the expression of a primary increase in cervical sympathetic outflow may have been prevented in some cases by a secondary deficit, or by the inhibitory effects of prophylactic medication. Sympathetic activity could also alter during different stages of the headache cycle. For example, Lance et $a l$ hypothesised that an increase in activity of the locus coeruleus (a noradrenergic "sympathetic" nucleus in the brainstem) could initiate the vascular changes of migraine, whereas a secondary "fatigue" phase could disrupt pain control pathways descending from the locus coeruleus.

Ptosis developed less consistently than miosis during headache and recovered to a greater extent than miosis during the headache-free interval, both in the present series of patients and in others studied during attacks of cluster headache. ${ }^{24}$ These findings suggest that sympathetic fibres innervating the pupils are more vulnerable to persistent loss of function or damage than those innervating the eyelids. The dissociation between ptosis and miosis in cluster headache was noted by Riley and Moyer ${ }^{25}$ who suggested that fibres destined for the eyelids and pupils may separate within the internal carotid plexus. If so, sympathetic dysfunction in migraine headache may sometimes originate after fibres separate in the carotid canal, or in their course along peripheral branches of the trigeminal nerve or at the end-organ itself.

In conclusion, increases in facial blood flow and decreases in cervical sympathetic outflow may be secondary consequences of trigeminal nerve activity during migraine. Mediation of vascular changes and miosis during headache by a central decrease in cervical sympathetic outflow is less likely, because ptosis during headache was inconsistent and miosis persisted during the headache-free interval. Repeated observations throughout the course of headache episodes are needed to determine whether cervical sympathetic outflow alters during different phases of the attack and whether a secondary sympathetic deficit masks a primary increase in sympathetic activity on the symptomatic side of the face.

This study was carried out with the support and encouragement of Professor JW Lance and received financial assistance from the National Health and Medical Research Council of Australia, and the JA Perini and Adolph Basser Family Trusts. The photographic chamber was assembled by Mr JW Duckworth.

1 Graham JR, Wolff HG. Mechanisms of migraine headache and action of ergotamine tartrate. AMA Arch Neurol Psychiatry 1938;39:737-63.

2 Jensen $K$. Headache and extracerebral blood flow. In: Olesen J, Edvinsson L, eds. Basic Mechanisms of Headache. Amsterdam: Elsevier, 1988:313-20.

3 Drummond PD, Lance JW. Extracranial vascular changes and the source of pain in migraine headache. Ann Neurol 1983;13:32-7.

4 Drummond PD, Lance JW. Facial temperature in migraine, tension-vascular and tension headache. Cephalalgia 1984; 4:149-58.

5 Drummond PD. Extracranial vascular changes during headache, exercise and stress. J Psychosom Res 1984; 28:133-8.

6 Moskowitz MA, Reinhard JF, Romero J, Melamed E, Pettibone DJ. Neurotransmitters and the fifth cranial Pettibone DJ. Neurotransmitters and the fifth cranial nerve: is there a relation to

7 Lance JW, Lambert GA, Goadsby PJ, Duckworth JW. Brainstem influences on the cerebral circulation: experimental data from cat and monkey of relevance to the mechanism of migraine. Headache 1983;23:258-65.

8 Drummond PD, Lance JW. Facial flushing and sweating mediated by the sympathetic nervous system. Brain 1987;110:793-803.

9 Schoenen J, Maertens de Noordhout A. The role of the sympathetic nervous system in migraine and cluster headache. In: Olesen J, Edvinsson L, eds. Basic Mechanisms of Headache. Amsterdam: Elsevier, 1988:393-410.

0 Fanciullacci $M$. Iris adrenergic impairment in idiopathic headache. Headache 1979;19:8-13. 
11 Gotoh F, Komatsumoto S, Araki N, Gomi S. Noradrenergic nervous activity in migraine. Arch Neurol 1984;41:951-5.

12 Yamamoto M, Meyer JS. Hemicranial disorder of vasomotor adrenoceptors in migraine and cluster headvasomotor adrenoceptors in migra

13 Ostfield AM, Wolff HG. Identification, mechanisms and management of the migraine syndrome. Med Clin North Am 1958;42:1497-509.

14 Drummond PD. Pupil diameter in migraine and tension headache. J Neurol Neurosurg Psychiatry 1987;50:228-30.

15 Lowenstein O, Loewenfeld IE. Role of sympathetic and parasympathetic systems in reflex dilatation of the pupil. Arch Neurol Psychiatry 1950;64:313-40.

16 Lowenstein O, Loewenfeld IE. Mutual role of sympathetic and parasympathetic in shaping of the pupillary reflex to light. Arch Neurol Psychiatry 1950;64:341-77.

17 Walsh FB, Hoyt WF. Clinical Neuro-ophthalmology, Vol 1. 3rd ed. Baltimore: Williams and Wilkins, 1969:517.

18 Headache Classification Committee of the International Headache Society. Classification and diagnostic criteria for headache disorders, cranial neuralgias and facial pain.
Cephalalgia 1988;8:Suppl 7

19 Loewenfeld IE, Rosskothen HD. Infrared pupil camera. A new method for mass screening and clinical use. $A m J$ Ophthalmol 1974;78:304-13.

20 Bickerstaff ER. Complicated migraine. In: Clifford Rose F, ed. Progress in Migraine Research. Vol 2. Bath: Pitman Press, 1984:83-101.

21 Lambert GA, Bogduk N, Goadsby PJ, Duckworth JW, Lance JW. Decreased carotid arterial resistance in cats in response to trigeminal stimulation. $J$ Neurosurg 1984;
$61: 307-15$.

22 Drummond PD. Autonomic disturbances in cluster headache. Brain 1988;111:1199-209.

23 Fanciullacci M, Fusco BM, Alessandri M, Campagnolo V, Sicuteri F. Unilateral impairment of pupillary response to trigeminal nerve stimulation in cluster headache. Pain 1989;36:185-91.

24 Drummond PD. Dysfunction of the sympathetic nervous system in cluster headache. Cephalalgia 1988;8:181-6.

25 Riley FC, Moyer NJ. Oculosympathetic paresis associated with cluster headaches. Am J Ophthalmol 1971;72:763-8.
A note on the work of Clarke of Clarke's column Of the many names perpetuated by eponymous titles in that rich era of descriptive neurology, the 19th century, those from France and Germany seem to predominate. Jackson, Ferrier and Gowers were of course colossi whose reputations bestrode international boundaries. There were many others of great distinction but of less fame.

Born in London, educated in France until the age of 13, Jacob Augustus Lockhart Clarke followed his grandfather and brother into medicine, studying at Guy's and St. Thomas' hospitals.

Whilst living with his mother in Pimlico he was engaged in general practice and it was here that he undertook his meticulous anatomical studies of the spinal cord and brain. He used spirits of wine and turpentine as fixatives. He distinguished the lateral from the medial cuneate (or "restiform") nucleus, and identified for the first time the nucleus intermediolateralis and the "posterior vesicular column" now known as Clarke's column.$^{1-3} \mathrm{He}$ experimented with techniques for preserving histological sections and devised the trick of mounting them in balsam. ${ }^{1}$

After Olliviers d'Angers and Gull he provided an early account of syringomyelia. His researches were chronicled in many papers in the Philosophical Transactions of the Royal Society and other distinguished journals. His titles included: "The intimate structure of the brain human and comparative: on the structure of the medulla oblongata"; "the development of striped muscle in Man, Mammalia, and Birds"; "On the nervous system of Lumbricus terrestris"; "On the structure of the optic lobes of the Cuttle-fish"; "On locomotor ataxy"; and, with Hughlings Jackson "On a case of muscular atrophy with disease of the spinal cord and medulla oblongata".

I am indebted to Mr Alan J Clark, Librarian at the Royal Society and to Mr Geoffrey Davenport, Librarian at the Royal College of Physicians for biographical data and references.

JMS PEARCE

1 Clarke JAL. Researches into the structure of the Spinal Cord [1850]. Philos Trans Roy Soc London 1851;141: 607-22.

2 Clarke JAL. Further researches on the grey substance of the Spinal Cord. ibid 1859;149:437-67.

3 Clarke JAL. Researches on the development of the Spinal Cord in man, mammalia, and birds. ibid 1862;911-38. 